\title{
Regulation of Endogenous Glucose Production by Glucose Per Se Is Impaired in Type 2 Diabetes Mellitus
}

\author{
Michèle Mevorach, Adria Giacca, Yigal Aharon, Meredith Hawkins, Harry Shamoon, and Luciano Rossetti \\ Department of Medicine, Diabetes Research Center, Albert Einstein College of Medicine, Bronx, New York 10461
}

\section{Abstract}

We examined the ability of an equivalent increase in circulating glucose concentrations to inhibit endogenous glucose production (EGP) and to stimulate glucose metabolism in patients with Type 2 diabetes mellitus (DM2). Somatostatin was infused in the presence of basal replacements of glucoregulatory hormones and plasma glucose was maintained either at 90 or $180 \mathrm{mg} / \mathrm{dl}$. Overnight low-dose insulin was used to normalize the plasma glucose levels in DM2 before initiation of the study protocol. In the presence of identical and constant plasma insulin, glucagon, and growth hormone concentrations, a doubling of the plasma glucose levels inhibited EGP by $42 \%$ and stimulated peripheral glucose uptake by $69 \%$ in nondiabetic subjects. However, the same increment in the plasma glucose concentrations failed to lower EGP, and stimulated glucose uptake by only $49 \%$ in patients with DM2. The rate of glucose infusion required to maintain the same hyperglycemic plateau was $58 \%$ lower in DM2 than in nondiabetic individuals. Despite diminished rates of total glucose uptake during hyperglycemia, the ability of glucose per se (at basal insulin) to stimulate whole body glycogen synthesis (glucose uptake minus glycolysis) was comparable in DM2 and in nondiabetic subjects. To examine the mechanisms responsible for the lack of inhibition of EGP by hyperglycemia in DM2 we also assessed the rates of total glucose output (TGO), i.e., flux through glucose-6phosphatase, and the rate of glucose cycling in a subgroup of the study subjects. In the nondiabetic group, hyperglycemia inhibited TGO by $35 \%$, while glucose cycling did not change significantly. In DM2, neither TGO or glucose cycling was affected by hyperglycemia. The lack of increase in glucose cycling in the face of a doubling in circulating glucose concentrations suggested that hyperglycemia at basal insulin inhibits glucose-6-phosphatase activity in vivo. Conversely, the lack of increase in glucose cycling in the presence of hyperglycemia and unchanged TGO suggest that the increase in the plasma glucose concentration failed to enhance the flux through glucokinase in DM2.

In summary, both lack of inhibition of EGP and diminished stimulation of glucose uptake contribute to impaired

Address correspondence to Dr. Harry Shamoon, Diabetes Research Center, Albert Einstein College of Medicine, 1300 Morris Park Avenue, Bronx, NY 10461. Phone: 718-430-2127; FAX: 718-430-8557; E-mail: shamoon@aecom.yu.edu

Received for publication 2 January 1998 and accepted in revised form 22 June 1998.

J. Clin. Invest.

(C) The American Society for Clinical Investigation, Inc. 0021-9738/98/08/0744/10 \$2.00

Volume 102, Number 4, August 1998, 744-753

http://www.jci.org glucose effectiveness in DM2. The abilities of glucose at basal insulin to both increase the flux through glucokinase and to inhibit the flux through glucose-6-phosphatase are impaired in DM2. Conversely, glycogen synthesis is exquisitely sensitive to changes in plasma glucose in patients with DM2. (J. Clin. Invest. 1998. 102:744-753.) Key words: endogenous glucose production • glucokinase - type 2 diabetes • hyperglycemia $\cdot$ glucose-6-phosphatase

\section{Introduction}

Type 2 diabetes mellitus (DM2) ${ }^{1}$ is a complex metabolic disorder with impairments in both insulin secretion and action (1-5). Insulin resistance can be demonstrated in patients with DM2 by means of the euglycemic hyperinsulinemic clamp technique (2-5). The impairment in insulin action under these experimental conditions includes diminished inhibition of endogenous glucose production (EGP) and decreased peripheral glucose uptake (2-5). The latter is largely accounted for by a marked decrease in the ability of insulin to promote glucose storage into skeletal muscle glycogen (6-11).

Hyperglycemia per se is also capable of increasing the disposal of glucose in peripheral tissues and of inhibiting EGP (12-19). In fact, it has been suggested that in patients with $\mathrm{DM} 2$, the plasma glucose concentration is increased at a critical level so as to compensate for insulin resistance (20-23). In support of the latter notion is the finding that when insulin clamp studies are performed at the individuals' fasting plasma glucose levels ("isoglycemic clamp"), patients with DM2 exhibit normal rates of glucose disposal and storage (21-23). Conversely, glucose effectiveness as assessed by either the Bergman Minimal Model or by a direct measurement of the glucose "area under the curve" is markedly decreased in patients with DM2 (24-26). Finally, increased basal EGP can be demonstrated in DM2 despite ambient hyperglycemia and normo- or hyperinsulinemia (1-3). This may be due, at least in part, to defective suppression of EGP by glucose per se at basal insulin.

Although the ability of glucose to promote its own disposal and to inhibit EGP in the presence of basal insulin has long been recognized (12-19), there are only a handful of studies which directly measured this parameter in nondiabetic humans or in patients with DM2 (26). Thus, it remains unclear whether these effects of glucose are preserved in patients with DM2. Overall, it has been clearly demonstrated that hyperglycemia per se markedly increases splanchnic glucose balance in nondiabetic individuals $(27,28)$, and that this effect is due to both enhanced splanchnic glucose uptake and decreased EGP (27,

1. Abbreviations used in this paper: BMI, body mass index; DM2, Type 2 diabetes mellitus; EGP, endogenous glucose production; Ra, rate of glucose appearance; Rd, rate of glucose disappearance; TGO, total glucose output. 
28). Suppression of EGP (12-17) and of total glucose output $(18,29,30)$ by hyperglycemia have also been demonstrated in nondiabetic subjects using isotope dilution techniques. Finally, in a recent study designed to directly assess basal glucose effectiveness in patients with DM2, Basu et al. have shown higher plasma glucose concentrations in response to an identical glucose infusion in patients with DM2 compared with nondiabetic subjects (26). In this study, estimates of the ability of the ambient glucose concentration to promote glucose disposal and to suppress EGP were both diminished (by 42 and by $29 \%$, respectively) in DM2. However, the difference in the glucose effect on EGP did not achieve statistical significance.

The aim of this study was to investigate the changes of EGP and peripheral glucose disposal in response to identical increments in the ambient glucose concentrations in patients with DM2 while maintaining the plasma concentrations of insulin, glucagon, and growth hormone at constant and basal levels. In the attempt to further clarify the mechanisms whereby glucose regulates EGP and glucose disposal in DM2, we also monitored the rates of total glucose output, glucose cycling, and glycolysis throughout the studies.

\section{Methods}

Subjects. We studied nine patients with DM2. Five patients were treated with short-acting oral sulfonylurea agents, three were treated with insulin, and one was treated with diet alone. The diabetic subjects had an average $\mathrm{HbA} 1 \mathrm{c}$ of $8.5 \pm 0.4 \%$ (NL $<6.1 \%)$, body mass index (BMI) of $27.6 \pm 1.1 \mathrm{~kg} / \mathrm{m}^{2}$, age of $57 \pm 2 \mathrm{yr}$, and duration of diabetes of $14 \pm 2 \mathrm{yr}$. Except for diabetes, all were in general good health. We also studied nine nondiabetic healthy volunteers with average BMI of $27.8 \pm 1.6 \mathrm{~kg} / \mathrm{m}^{2}$ and average age of $38 \pm 5 \mathrm{yr}$. This nondiabetic group was subdivided in age-matched controls $(n=4)$ with age of $52 \pm 7 \mathrm{yr}$ and BMI of $28.9 \pm 2.0 \mathrm{~kg} / \mathrm{m}^{2}$ and young controls $(n=5)$ with age of $26 \pm 2 \mathrm{yr}$ and BMI of $26.9 \pm 2.6 \mathrm{~kg} / \mathrm{m}^{2}$. None of the normal subjects was taking any medications and they had no family history of DM2. Eligibility for study was determined by history and physical examination and hematological and biochemical tests. Subjects with anemia, bleeding disorders, or recent weight changes were excluded. Informed written consent was obtained in accordance with the policy of the Committee on Clinical Investigations of the Albert Einstein College of Medicine.

Experimental design. The diabetic patients were admitted on the evening before the day of the study. Oral medications, if any, were discontinued $24 \mathrm{~h}$ before the study, and long-acting insulin was withheld the evening before the study. Beginning at 10:00 p.m., patients were asked to fast, and a variable intravenous infusion of insulin was started. The insulin infusion rate was adjusted according to an algorithm based on hourly blood glucose measurements (31). The next morning, the patients were transferred to the Clinical Research Unit and the experimental protocol was initiated. Nondiabetic subjects were admitted to the Clinical Research Unit on the morning of the study after an overnight fast.

An 18-gauge catheter was inserted in an antecubital vein for infusions and a contralateral hand vein was cannulated in a retrograde fashion for arterialized venous blood sampling. In order to obtain arterialized venous blood, this hand was kept in a warming plexiglass box maintained at $60^{\circ} \mathrm{C}$. The experimental protocols lasted $6 \mathrm{~h}$ and included three 120-min periods: a first euglycemic period, a second euglycemic period, and a third hyperglycemic period (Fig. 1). At $t=$ $-120 \mathrm{~min}$, a primed-continuous infusion of HPLC-purified $\left[3-{ }^{3} \mathrm{H}\right]$ glucose (New England Nuclear, Boston, MA) was started (prime infusion $22 \mu \mathrm{Ci}$; continuous infusion rate $0.15 \mu \mathrm{Ci} / \mathrm{min}$ ) via an indwelling catheter. In three normal subjects and in five diabetic patients, [2$\left.{ }^{3} \mathrm{H}\right]$ - and $\left[6-{ }^{3} \mathrm{H}\right]$ glucose (HPLC-purified, New England Nuclear) were infused instead (prime $18 \mu \mathrm{Ci}$ each; continuous infusion rate 0.13 $\mu \mathrm{Ci} / \mathrm{min}$ each). At $t=-120 \mathrm{~min}$, an infusion containing somatostatin $(250 \mu \mathrm{g} / \mathrm{h}$; Bachem, King of Prussia, PA), growth hormone $(3.0 \mathrm{ng} / \mathrm{kg}$ per min; Genentech, San Francisco, CA), and glucagon (1.0 ng/kg per min; Eli Lilly, Indianapolis, IN) was initiated and maintained throughout the study. This infusion was prepared with $1 \mathrm{mg} / \mathrm{ml}$ albumin diluted in saline. At $t=-120 \mathrm{~min}$, an infusion of insulin prepared in albumin-containing saline (Novolin Regular; Novo-Nordisk, Princeton, NJ) was also begun. Plasma glucose concentrations were measured at 10-min intervals and the rate of insulin infusion was adjusted to maintain euglycemia $(90-100 \mathrm{mg} / \mathrm{dl})$ without the need for exogenous glucose infusion. When a stable rate of insulin infusion was determined, it was kept constant for the remainder of the study. This occurred within the last $30 \mathrm{~min}$ of this first euglycemic period $(t=-30$ to $t=0)$.

During the second euglycemic period, the "individualized" basal rate of insulin infusion was kept constant and ambient euglycemia prevailed for $2 \mathrm{~h}$, until $t=120 \mathrm{~min}$. At $t=120 \mathrm{~min}$, plasma glucose levels were rapidly increased by $\sim 90 \mathrm{mg} / \mathrm{dl}$ and clamped at $\sim 180$ $\mathrm{mg} / \mathrm{dl}$ for the next $2 \mathrm{~h}$, until $240 \mathrm{~min}$, using an exogenous infusion of $20 \%$ dextrose. Tracers $\left(\left[3-{ }^{3} \mathrm{H}\right]\right.$ glucose or $\left[2-{ }^{3} \mathrm{H}\right]$ glucose and $\left[6-{ }^{3} \mathrm{H}\right]$ glucose) were added to the cold $20 \%$ dextrose $(\sim 0.1 \mu \mathrm{Ci} / \mathrm{ml})$ to maintain glucose specific activity constant during hyperglycemia (32). All other infusions were kept at the rate used during the second euglycemic period.

To discern the specific effects of the changes in the ambient glucose levels from potential time-dependent effects of the pancreatic clamp procedure per se, we restudied three nondiabetic and three diabetic patients with HPLC-purified $\left[3-{ }^{3} \mathrm{H}\right]$ glucose during continuous $6 \mathrm{~h}$ euglycemia. As in the hyperglycemic study, at $t=-120 \mathrm{~min}$, a primed continuous infusion of HPLC-purified $\left[3-{ }^{3} \mathrm{H}\right]$ glucose (New England Nuclear) was started (prime infusion $22 \mu \mathrm{Ci}$; continuous infusion rate $0.15 \mu \mathrm{Ci} / \mathrm{min}$ ), as well as infusions of somatostatin (250 $\mu \mathrm{g} / \mathrm{h})$, growth hormone (3.0 $\mathrm{ng} / \mathrm{kg}$ per min), and glucagon $(1.0 \mathrm{ng} / \mathrm{kg}$ per min), and maintained throughout. In this protocol (designated as "Time-Control Study"), the rates of insulin infusion were carefully reproduced to match those used during the euglycemic-hyperglycemic study in the same individual, but euglycemia was maintained during the entire study (i.e., the third period hyperglycemia was replaced by a third euglycemic period). Blood withdrawal procedures were performed identically as in the hyperglycemic studies. Thus, a total of 22 six-hour pancreatic clamp studies were performed, 16 of which were conducted with a final hyperglycemic period and 6 of which were time-control studies.

At the completion of the study, the tracer, glucose and hormone infusions were stopped. The insulin infusion was continued in the diabetic patients for an additional $30 \mathrm{~min}$. A meal was provided and subjects were discharged. Diabetic individuals resumed their usual regimens.

Blood was sampled at 5-min intervals for measurement of plasma glucose, at 15-min intervals for glucose specific activity, plasma insulin, glucagon, epinephrine, and norepinephrine, at 30-min intervals for free fatty acids (FFA) and glycerol, and at 60-min intervals for cortisol and growth hormone. Continuous indirect calorimetry was performed for a 20-min period at $95 \mathrm{~min}$ and again at $215 \mathrm{~min}$. Protein oxidation was estimated from the urinary urea production measured on a urine sample obtained at the end of the procedure.

Analytical procedures. Plasma glucose was measured with a glucose analyzer (Beckman Instruments, Inc., Fullerton, CA) by use of the glucose oxidase method. Plasma $\left[3-{ }^{3} \mathrm{H}\right]$ glucose radioactivity was measured in duplicate on the supernatants of barium hydroxide-zinc sulfate precipitates (Somogyi procedure) of plasma samples after evaporation to dryness to eliminate tritiated water. Plasma-tritiated water specific activity was determined by liquid scintillation counting of the protein-free supernatant (Somogyi filtrate) before and after evaporation to dryness. Separation of $\left[2-{ }^{3} \mathrm{H}\right]-$ and $\left[6-{ }^{3} \mathrm{H}\right]$ glucose was achieved by dimedon precipitation as described by Efendic et al. (29). Briefly, after deproteinization of plasma samples, the supernatant was passed through anion and cation exchange chromatography (AG 
2-X8 and AG 50 W-X8; Bio-Rad Laboratories, Richmond, CA). An aliquot of the eluate was evaporated to dryness and after addition of water and liquid scintillation solution, the total radioactivity from [2$\left.{ }^{3} \mathrm{H}\right]-$ and $\left[6-{ }^{3} \mathrm{H}\right]$ glucose was measured by beta scintillation counting. The radioactivity of $\left[6{ }^{-3} \mathrm{H}\right]$ glucose was determined in an aliquot of the eluate as described by Dunn et al. (33). First, $10 \mathrm{mg}$ of glucose was added to $2 \mathrm{ml}$ of the eluate as a carrier. Glucose was then oxidized with periodate to five molecules of formic acid (derived from carbons 1-5) and one molecule of formaldehyde (derived from carbon 6). After addition of dimedon, formaldehyde precipitates as formaldemethone. The radioactivity of the precipitate was determined after filtering, drying, and weighing. In all subjects studied, the recovery for $\left[6-{ }^{3} \mathrm{H}\right]$ glucose by the dimedon procedure was quite reproducible and $\sim 90 \%$. The radioactivity of $\left[2-{ }^{3} \mathrm{H}\right]$ glucose was calculated as the difference between total radioactivity and that of $\left[6-{ }^{3} \mathrm{H}\right]$ glucose. Aliquots of the infusate tracer mixture were run in parallel with the plasma samples through the dimedon procedure.

Plasma insulin, glucagon, growth hormone, and cortisol were determined by RIA (34). Plasma epinephrine and norepinephrine were measured using an isotope derivative assay (34). Plasma FFA and glycerol were measured using colorimetric enzymatic methods (31) and plasma lactate by an enzymatic spectrophotometric assay (35). For indirect calorimetry, air flow, $\mathrm{O}_{2}$, and $\mathrm{CO}_{2}$ concentrations in the expired and inspired air were measured by a computerized open-circuit system (Deltatrac; Sensormedics, Yorba Linda, CA). Urinary nitrogen was measured by the Kjeldahl procedure (36). HbA1c was measured by ion-exchange chromatography with an upper normal limit of $6.1 \%$.

Calculations. Rates of glucose appearance ( $\mathrm{Ra}$ ) and disappearance ( $\mathrm{Rd})$ were calculated using Steele's steady-state equation (37). Total glucose output (TGO) and endogenous glucose production (EGP) were determined by subtracting the rates of glucose infusion from the tracer-determining Ra. TGO was calculated using the Ra measured with 2-[ $\left.{ }^{3} \mathrm{H}\right]$ glucose, while EGP was calculated using the $\mathrm{Ra}$ measured with either $\left[3-{ }^{3} \mathrm{H}\right]-$ or $\left[6-{ }^{3} \mathrm{H}\right]$ glucose. In the studies in which both $\left[2-{ }^{3} \mathrm{H}\right]$ glucose and $\left[6-{ }^{3} \mathrm{H}\right]$ glucose were infused, glucose cycling was calculated as the difference between TGO and EGP. Rates of glycolysis from plasma glucose were estimated from the increment per unit time in tritiated water (disintegrations per minute per milliliter per minute) multiplied by body water mass (in milliliters) per [3${ }^{3} \mathrm{H}$ ]glucose specific activity (disintegrations per minute per milligram) as previously validated $(38,39)$. Glycogen synthetic rates were estimated as the difference between glucose disposal rate $\left(R_{d}\right)$ and glycolysis from plasma glucose $(38,39)$. Carbohydrate oxidation was calculated from $\mathrm{O}_{2}$ consumption and $\mathrm{CO}_{2}$ production (corrected for protein oxidation) with the equations of Lusk (40). Data for glucose turnover, carbohydrate and lipid oxidation, plasma hormones, and substrate concentrations represent the mean values during the final $60 \mathrm{~min}$ of the euglycemic period and the final $60 \mathrm{~min}$ of the hyperglycemic period. For the glucose cycling data, the results represent the average values for the entire euglycemic period and the final $60 \mathrm{~min}$ of the hyperglycemic period. Since during the time-control studies, euglycemia was maintained throughout the three 2 -h periods of the procedure, we will refer to the time period that corresponds to the hyperglycemic clamp as the "third" euglycemic period. The results represent the mean values during the last $60 \mathrm{~min}$ of the second euglycemic period (60-120 $\mathrm{min}$ ), and the final $60 \mathrm{~min}$ of the third euglycemic period (180-240 min).

Statistical analysis of the data over time was performed using PROC MIXED in SAS System Version 6.12 (SAS Institute, Cary, NC). The random effect considered in this mixed model is the error measurement of individual subjects, and the within individual fixed effect is the difference between groups. For averaged data, Student's $t$ test was used.

\section{Results}

Plasma glucose and insulin concentrations (Fig. 1). After overnight fast and insulin infusion, plasma glucose concentrations were similar and plasma insulin concentrations were higher $(21 \pm 5$ vs. $10 \pm 1 \mu \mathrm{U} / \mathrm{ml})$ in the patients with DM2 compared with those in the overnight-fasted nondiabetic subjects. The rate of overnight insulin infusion averaged $2.8 \pm 0.6 \mathrm{U} / \mathrm{h}$ and plasma glucose targets of $80-150 \mathrm{mg} / \mathrm{dl}$ were maintained without hypoglycemia. On the morning of study, plasma glucose averaged $107 \pm 9 \mathrm{mg} / \mathrm{dl}$ in diabetic subjects and $100 \pm 1 \mathrm{mg} / \mathrm{dl}$ in nondiabetic subjects. During the first euglycemic period (insulin adjustment period) after initiation of infusions of somatostatin and hormone replacement, plasma glucose concentrations rose slightly in nondiabetic subjects and were then gradually reduced to $\sim 90 \mathrm{mg} / \mathrm{dl}$ (Fig. 1). Plasma glucose was similar in the diabetic and in the nondiabetic subjects during the second euglycemic and the hyperglycemic study periods $(94 \pm 1$ vs. $90 \pm 3 \mathrm{mg} / \mathrm{dl}, P<0.05 ; 187 \pm 4$ vs. $180 \pm 1 \mathrm{mg} / \mathrm{dl}, P=$ NS, respectively). Similarly, the amplitude of the change in the ambient glucose concentrations generated with the hyperglycemic clamp was identical in the two groups.

The average insulin infusion rate needed to maintain euglycemia during the final $30 \mathrm{~min}$ of the insulin adjustment period and thereafter was similar in the two groups $(0.19 \mathrm{mU} / \mathrm{kg}$ per min for the diabetic patients, $0.21 \mathrm{mU} / \mathrm{kg}$ per min for the nondiabetic subjects, $P=\mathrm{NS}$ ). In addition, the insulin concentrations remained comparable between the two groups and, most important, they were not different during euglycemia and hyperglycemia $(19 \pm 4 \mu \mathrm{U} / \mathrm{ml}$ vs. $18 \pm 2 \mu \mathrm{U} / \mathrm{ml} ; 17 \pm 4 \mu \mathrm{U} / \mathrm{ml}$ vs. $19 \pm 3 \mu \mathrm{U} / \mathrm{ml}$, diabetic vs. nondiabetic subjects, euglycemia and hyperglycemia, respectively; all $P=\mathrm{NS}$ ).

Other hormones and substrates (Fig. 2, and Table I). Plasma glucagon and growth hormone concentrations were similar in the two groups and comparable during all periods (Fig. 2). Plasma C-peptide concentrations were rapidly suppressed by the somatostatin and insulin infusions and they remained unchanged and similar in the two groups throughout the study (Fig. 2). During both periods, the plasma FFA concentrations (Fig. 2) were higher in the diabetic than the nondi-

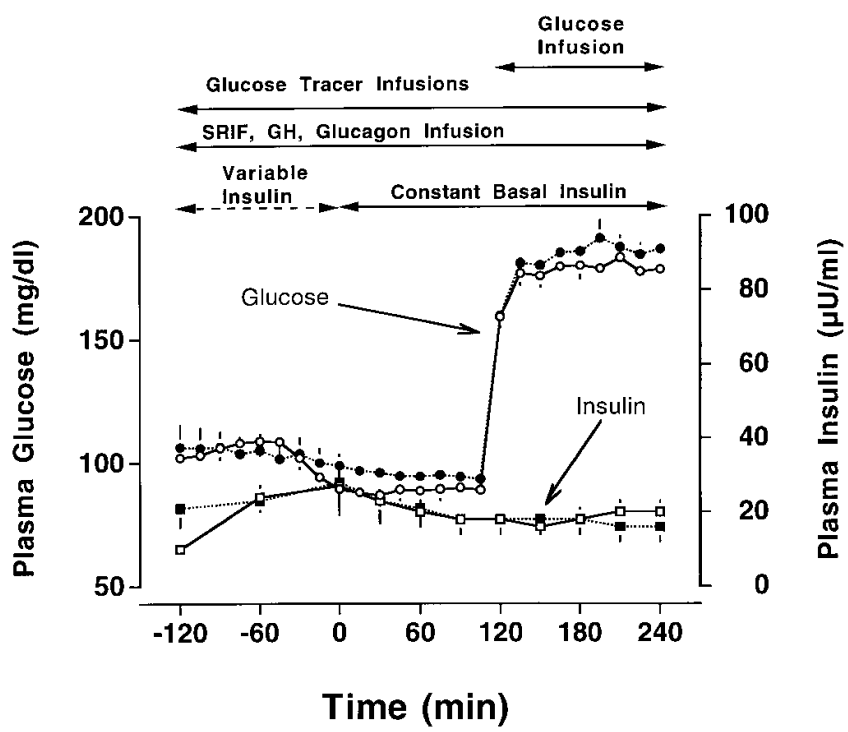

Figure 1. Plasma glucose and insulin concentrations during euglycemic-hyperglycemic clamp studies. Nondiabetic subjects, open circles or squares; Type 2 diabetic subjects, filled circles or squares. 

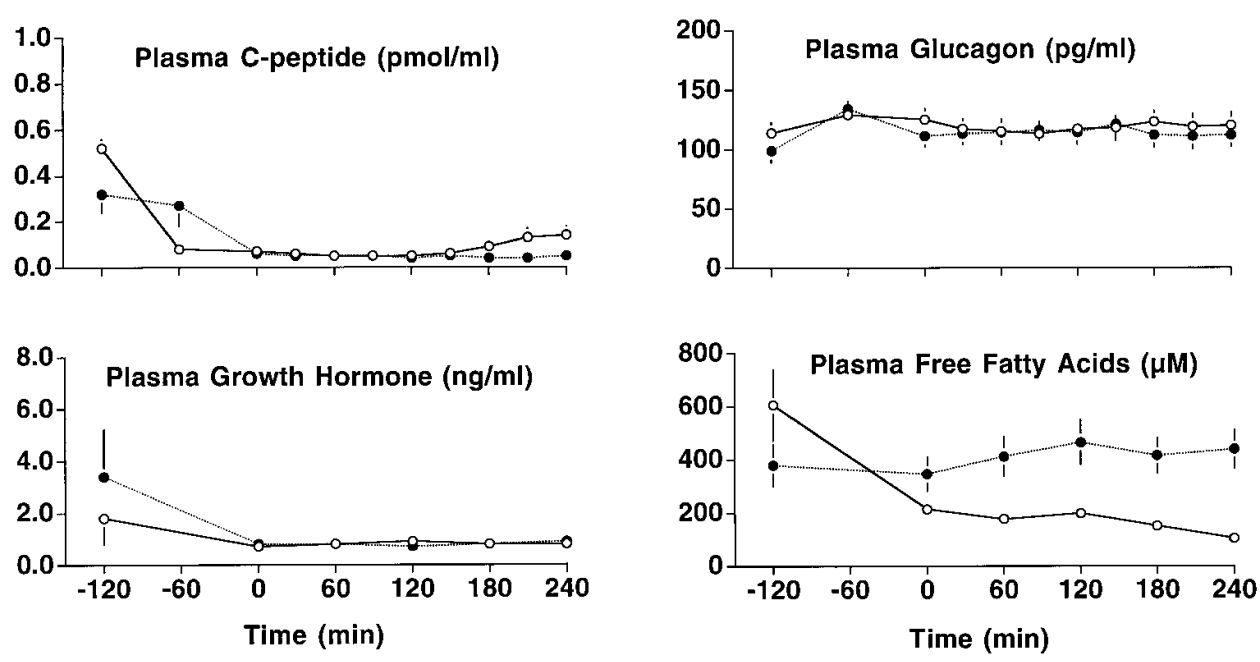

Figure 2. Plasma glucagon, C-peptide, growth hormone, and plasma FFA concentrations in nondiabetic (open circles) and Type 2 diabetic (filled circles) subjects during euglycemic-hyperglycemic clamp studies.

abetic subjects $(P<0.05$ for euglycemia; $P=0.005$ for hyperglycemia). During hyperglycemia, there was a small further drop in the plasma FFA levels in the nondiabetic group $(P<$ $0.01)$, while there was no decline in plasma FFA concentrations in the diabetic patients. The plasma concentrations of the remaining hormones and substrates are summarized in Table I. Plasma epinephrine and cortisol concentrations were similar in the two groups and comparable during all study periods. Norepinephrine concentrations were slightly higher in the diabetic subjects than the nondiabetic ones during euglycemia $(P<0.05)$ and hyperglycemia $(P<0.01)$. However, the plasma norepinephrine levels were unchanged by hyperglycemia in both groups. Plasma lactate and glycerol concentrations were similar and unchanged throughout the duration of the protocol.

Time-control studies. To examine the time-dependent effects of our pancreatic clamp procedure per se in nondiabetic and diabetic subjects, a subgroup of subjects from both groups was restudied on a separate day. On this occasion, all infusions were identical to those used during the first study but euglycemia was maintained during the entire $6 \mathrm{~h}$ of the study. The plasma glucose concentration was similar in the two groups and remained stable throughout the duration of the study (104 \pm 5 and $113 \pm 9 \mathrm{mg} / \mathrm{dl}$ for the second euglycemic period, respectively, $97 \pm 4.0$ and $99 \pm 8.0 \mathrm{mg} / \mathrm{dl}$ for the third euglycemic period, respectively; diabetic vs. nondiabetic subjects, $P=\mathrm{NS}$ for both periods). Plasma insulin concentrations were likewise comparable between the two groups and similar during both time periods $(17 \pm 8$ and $16 \pm 8 \mu \mathrm{U} / \mathrm{ml}$ for diabetic subjects, respectively; $12 \pm 4$ and $12 \pm 3 \mu \mathrm{U} / \mathrm{ml}$ for the nondiabetic subjects, respectively, $P=\mathrm{NS}$ ). The concentrations of other hormones and substrates (not shown) were also stable throughout the study and similar to those measured during the euglycemic periods of the first protocol. Some glucose was infused during the last $120 \mathrm{~min}$ of the time control studies to maintain euglycemia. However, this rate of glucose infusion was quite small $(\sim 0.3 \mathrm{mg} / \mathrm{kg}$ per $\mathrm{min})$ and similar in the diabetic and nondiabetic individuals.

Rates of glucose infusion. The average rate of infusion of glucose required to maintain the target hyperglycemic plateau during the last $60 \mathrm{~min}$ of the hyperglycemic period was decreased by $58 \%$ in DM2 compared with nondiabetic individu- als $(1.08 \pm 0.25$ vs. $2.60 \pm 0.22 \mathrm{mg} / \mathrm{kg}$ per min, diabetic vs. nondiabetic subjects). Since there were no differences in glucose infusion rates during any of the euglycemic periods, including the third study period of the time-control protocol, this difference is interpreted as indicating a marked decrease in "glucose effectiveness" in DM2. The latter impairment may underlie defects in either or both the ability of hyperglycemia at basal insulin to suppress EGP and to promote glucose uptake and metabolism in peripheral tissues. Thus, glucose isotope dilution techniques were used to monitor the rates of peripheral glucose uptake and metabolism and of EGP during euglycemia and hyperglycemia. The average glucose specific activities during euglycemia and hyperglycemia for each tracer are summarized in Fig. 3. Glucose specific activity was maintained constant after tracer equilibration, euglycemia, and hyperglycemia in each group.

Whole body glucose uptake (Fig. 4). During the time-control studies, the rates of whole body glucose uptake were slightly $(P=\mathrm{NS})$ lower in DM2 than in the nondiabetic group but they were unchanged during the second and third study periods in both groups $(2.23 \pm 0.24$ vs. $2.52 \pm 0.34 \mathrm{mg} / \mathrm{kg}$ per min, respectively, and $2.11 \pm 0.29$ vs. $2.40 \pm 0.06 \mathrm{mg} / \mathrm{kg}$ per min,

Table I. Plasma Hormone and Substrate Concentrations during Euglycemic-Hyperglycemic Clamp Studies

\begin{tabular}{lccccc}
\hline & \multicolumn{2}{c}{ Nondiabetic subjects } & & \multicolumn{2}{c}{ Type 2 diabetic subjects } \\
\cline { 2 - 3 } \cline { 5 - 6 } & Euglycemia & Hyperglycemia & & Euglycemia & Hyperglycemia \\
\hline $\begin{array}{c}\text { Epinephrine } \\
\quad(\mathrm{pg} / \mathrm{ml})\end{array}$ & $56 \pm 18$ & $61 \pm 25$ & & $59 \pm 36$ & $33 \pm 11$ \\
$\begin{array}{c}\text { Norepinephrine } \\
\quad(\mathrm{pg} / \mathrm{ml})\end{array}$ & $161 \pm 13$ & $135 \pm 8$ & & $209 \pm 14^{*}$ & $198 \pm 15^{\ddagger}$ \\
Cortisol $(\mu \mathrm{g} / \mathrm{dl})$ & $6 \pm 1$ & $8 \pm 2$ & & $10 \pm 2$ & $9 \pm 2$ \\
$\begin{array}{c}\text { Lactate } \\
(\mathrm{mmol} / \mathrm{liter})\end{array}$ & $0.81 \pm 0.08$ & $0.85 \pm 0.09$ & & $0.62 \pm 0.08$ & $0.61 \pm 0.09$ \\
Glycerol $(\mu \mathrm{M})$ & $38 \pm 5$ & $40 \pm 5$ & & $51 \pm 6$ & $51 \pm 7$ \\
& & & & \\
\hline
\end{tabular}

${ }^{*} P<0.05, \mathrm{DM} 2$ vs. nondiabetic subjects at equivalent time periods; ${ }^{\ddagger} P<$ $0.01, \mathrm{DM} 2$ vs. nondiabetic subjects at equivalent time periods. 

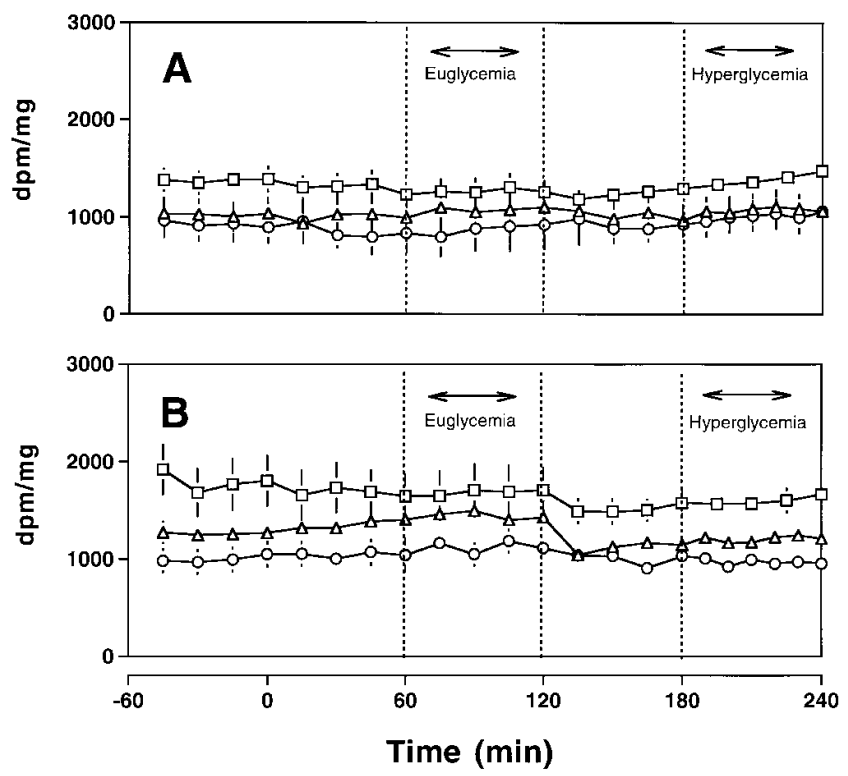

Figure 3. Glucose specific activities during euglycemic-hyperglycemic clamp studies. Results from studies using $\left[3-{ }^{3} \mathrm{H}\right]$ glucose are represented by square symbols, from $\left[2-{ }^{3} \mathrm{H}\right]$ glucose by circles, and from [6${ }^{3} \mathrm{H}$ ]glucose by triangles. $(A)$ Nondiabetic subjects; $(B)$ Type 2 diabetic subjects.

respectively, diabetic vs. nondiabetic subjects, second and third euglycemic period, respectively; $P=\mathrm{NS}$ ). During euglycemia, whole body glucose uptake also tended to be slightly lower in the diabetic than in the nondiabetic subjects on the day of the hyperglycemic study $(1.80 \pm 0.08$ vs. $2.25 \pm 0.18 \mathrm{mg} /$ $\mathrm{kg}$ per min, $P=\mathrm{NS})$. During hyperglycemia, however, whole body glucose uptake was markedly lower $(30 \%)$ in the diabetic than in the nondiabetic subjects $(2.68 \pm 0.17$ vs. $3.81 \pm 0.23 \mathrm{mg} /$ $\mathrm{kg}$ per $\min , P<0.005)$. Moreover, during this period, whole body glucose uptake increased by $49 \%(P<0.0001)$ in the diabetic subjects and by $69 \%(P<0.005)$ in the nondiabetic individuals. The effect of hyperglycemia per se on whole body glucose uptake was similar in the age-matched $(2.11 \pm 0.17$ to $3.77 \pm 0.15 \mathrm{mg} / \mathrm{kg}$ per $\mathrm{min}$ ) and young (2.39 \pm 0.34 to $3.86 \pm 0.48$ $\mathrm{mg} / \mathrm{kg}$ per $\mathrm{min}$ ) nondiabetic subgroups.

Glycolysis and glycogen synthesis (Fig. 5). Glycolysis from plasma glucose was evaluated in the nondiabetic and diabetic subjects who received $\left[3-{ }^{3} \mathrm{H}\right]$ glucose infusions. During euglycemia, the glycolytic rates from plasma glucose were similar in the diabetic and in the nondiabetic groups $(1.54 \pm 0.14$ vs. $1.59 \pm 0.16 \mathrm{mg} / \mathrm{kg}$ per min, respectively; diabetic vs. nondiabetic subjects, $P=\mathrm{NS}$ ). During hyperglycemia, the glycolytic rate remained unchanged in the diabetic subjects (to $1.40 \pm 0.23 \mathrm{mg}$ / kg per min, $P=\mathrm{NS}$ ), whereas it tended to increase in the nondiabetic subjects (to $2.03 \pm 0.2 \mathrm{mg} / \mathrm{kg}$ per min, $P=0.0768$ ). Glycogen synthesis tended to be lower in the diabetic subjects than in the nondiabetic subjects during euglycemia (Fig. 5). However, glycogen synthesis increased significantly during hyperglycemia in both DM2 and nondiabetic subjects $(0.36 \pm 0.06$ to $1.50 \pm 0.33 \mathrm{mg} / \mathrm{kg}$ per min, respectively, for diabetic subjects; euglycemia vs. hyperglycemia, $P<0.05 ; 0.67 \pm 0.14$ to $1.74 \pm$ $0.39 \mathrm{mg} / \mathrm{kg}$ per min, respectively, for the nondiabetic subjects; euglycemia vs. hyperglycemia, $P<0.05$ ) (Fig. 5). During this
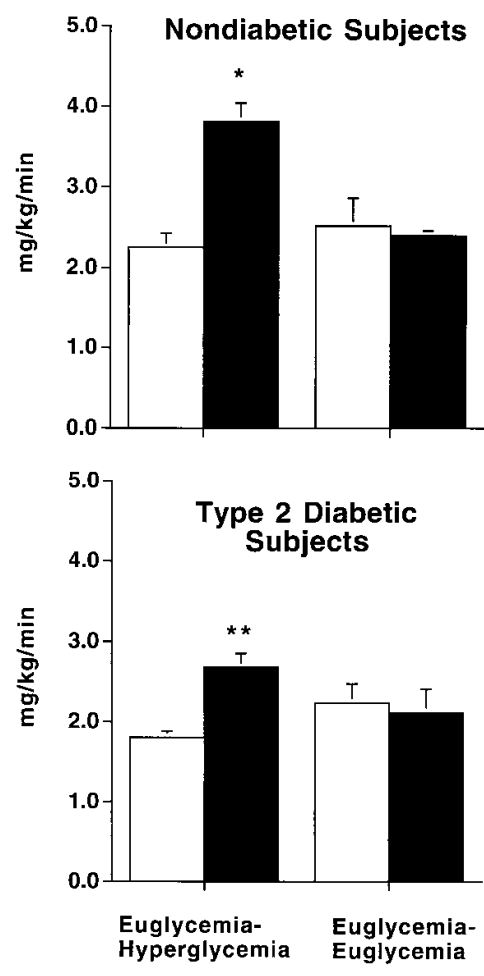

Figure 4. Whole body glucose uptake during euglycemic-hyperglycemic mia-Hyperglycemia) compared with that during time control (Euglycemia-Euglycemia) studies. Open bars, initial period of euglycemia; filled bars, represent the comparison study period (either euglycemia or hyperglycemia). $* P<0.005$ in nondiabetic subjects, euglycemia vs. hyperglycemia. $* * P<0.0001$ in Type 2 diabetic subjects, euglycemia vs. hyperglycemia. There were no significant changes in the time-control studies in either group. experiments (Euglyce-

period, glycogen synthesis was completely normalized in DM2 subjects.

Glucose oxidation and lipid oxidation. Glucose oxidation was slightly lower in the diabetic subjects during both periods but the differences were not statistically significant $(0.66 \pm 0.11$ vs. $0.89 \pm 0.19 \mathrm{mg} / \mathrm{kg}$ per $\mathrm{min}, P=\mathrm{NS}$, and $0.81 \pm 0.14$ vs. $1.14 \pm 0.2 \mathrm{mg} / \mathrm{kg}$ per min, $P=\mathrm{NS}$; diabetic vs. nondiabetic subjects, euglycemia and hyperglycemia, respectively). In both groups, glucose oxidation increased modestly during hyperglycemia. Lipid oxidation was likewise similar in the two groups during both periods $(0.84 \pm 0.11$ vs. $0.83 \pm 0.14 \mathrm{mg} / \mathrm{kg}$ per min during euglycemia, $0.74 \pm 0.09$ vs. $0.77 \pm 0.13 \mathrm{mg} / \mathrm{kg}$ per min during hyperglycemia; diabetic vs. nondiabetic subjects).

EGP (Figs. 6 and 7). During the time-control study, EGP was similar in the two groups during both periods. There was also a tendency toward lower EGP during the third than during the second euglycemic period in both DM2 and nondiabetic individuals. EGP was also similar in the two groups during the second euglycemic period on the day of the hyperglycemic study $(1.80 \pm 0.08$ vs. $2.09 \pm 0.19 \mathrm{mg} / \mathrm{kg}$ per min; diabetic vs. nondiabetic subjects, $P=$ NS) (Fig. 6). However, during hyperglycemia, EGP decreased by $42 \%$ in the nondiabetic whereas it remained unchanged in DM2 subjects $(2.09 \pm 0.19$ to $1.21 \pm 0.12$ $\mathrm{mg} / \mathrm{kg}$ per min in nondiabetic group, euglycemia vs. hyperglycemia, $P<0.005 ; 1.80 \pm 0.08$ to $1.68 \pm 0.08 \mathrm{mg} / \mathrm{kg}$ per $\mathrm{min}$ in the diabetic subjects, euglycemia vs. hyperglycemia, $P=$ NS). Furthermore, when the EGP measured during the corresponding period of the time control study was compared with the hyperglycemic period (Fig. 6), it was significantly higher in the nondiabetic ( $2.13 \pm 0.30$ vs. $1.21 \pm 0.12 \mathrm{mg} / \mathrm{kg}$ per $\mathrm{min}, P<0.05)$ but not in the DM2 $(1.67 \pm 0.17$ vs. $1.68 \pm 0.08 \mathrm{mg} / \mathrm{kg}$ per $\mathrm{min}, P=$ NS) group. The effect of hyperglycemia per se on EGP was similar in the age-matched $(1.80 \pm 0.09$ vs. $1.03 \pm 0.13 \mathrm{mg} / \mathrm{kg}$ per 

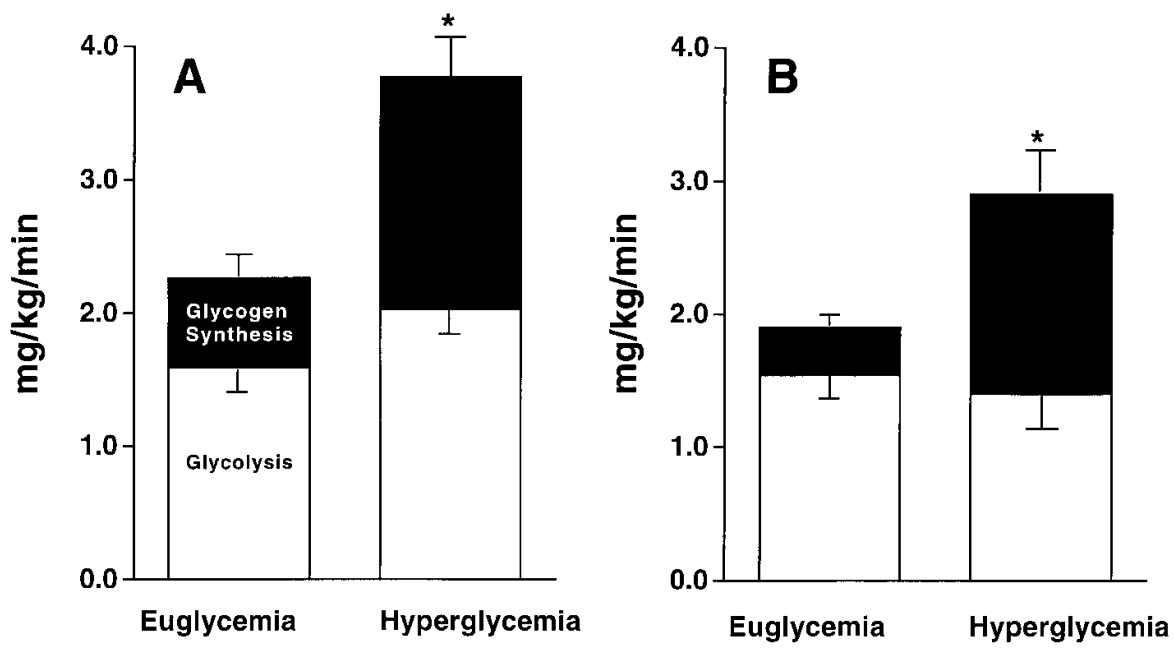

Figure 5. Glycolysis (open bars) and glycogen synthesis (filled bars) during euglycemic-hyperglycemic experiments. $(A)$ Nondiabetic subjects; $(B)$ Type 2 diabetic subjects. $* P<0.05$ for glycogen synthesis, euglycemia vs. hyperglycemia in both groups. See text for details.

$\mathrm{min})$ and young ( $2.37 \pm 0.32 \mathrm{vs} .1 .39 \pm 0.16 \mathrm{mg} / \mathrm{kg}$ per $\mathrm{min})$ nondiabetic controls.

Total glucose output and glucose cycling (Fig. 7). The changes in EGP in response to hyperglycemia were quite similar in the subgroups receiving double tracer $\left(\left[2-{ }^{3} \mathrm{H}\right]-\right.$ and $[6-$ $\left.{ }^{3} \mathrm{H}\right]$ glucose) infusions with $39 \%$ suppression of EGP in the nondiabetic individuals and lack of effect in the DM2 patients (Fig. 7, left). Similarly, TGO, which is a measure of the flux through glucose-6-phosphatase, was inhibited by $35 \%$ by hyperglycemia at basal insulin in the nondiabetic individuals, while it was unchanged by hyperglycemia in the DM2 patients (Fig. 7, middle). Glucose cycling was measured as the difference between TGO (measured with $\left[2-{ }^{3} \mathrm{H}\right]$ glucose) and EGP (measured with [6- $\left.{ }^{3} \mathrm{H}\right]$ glucose). In both groups of subjects, glucose cycling (Fig. 7, right) did not change significantly during hyperglycemia $(0.61 \pm 0.16$ vs. $0.66 \pm 0.19 \mathrm{mg} / \mathrm{kg}$ per $\mathrm{min}$ for $\mathrm{DM} 2 ; 0.73 \pm 0.27$ vs. $0.56 \pm 0.17 \mathrm{mg} / \mathrm{kg}$ per min for the nondia-
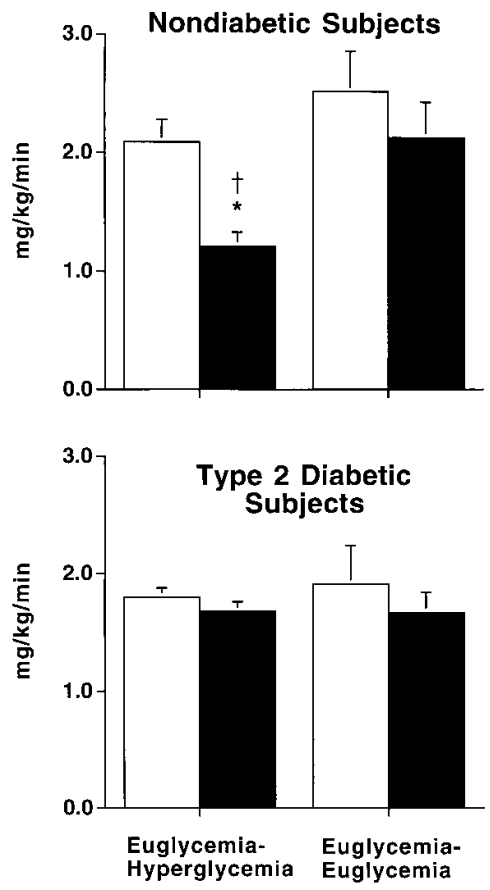

Figure 6. Endogenous glucose production during euglycemic-hyperglycemic experiments (Euglycemia-Hyperglycemia) compared with that during time control (Euglycemia-Euglycemia) studies. Open bars, initial period of euglycemia; filled bars, comparison study period (either euglycemia or hyperglycemia). $* P<0.005$ in nondiabetic subjects, euglycemia vs. hyperglycemia. ${ }^{\dagger} P<0.05$ for Type 2 diabetic vs. nondiabetic subjects during hyperglycemia. betic subjects, euglycemia vs. hyperglycemia, $P=$ NS for both groups). Glucose cycling expressed as a percentage of EGP was slightly increased by hyperglycemia in nondiabetic individuals (by $25 \%$ ) and at a lesser extent in DM2 patients (by $10 \%$; $P=$ NS).
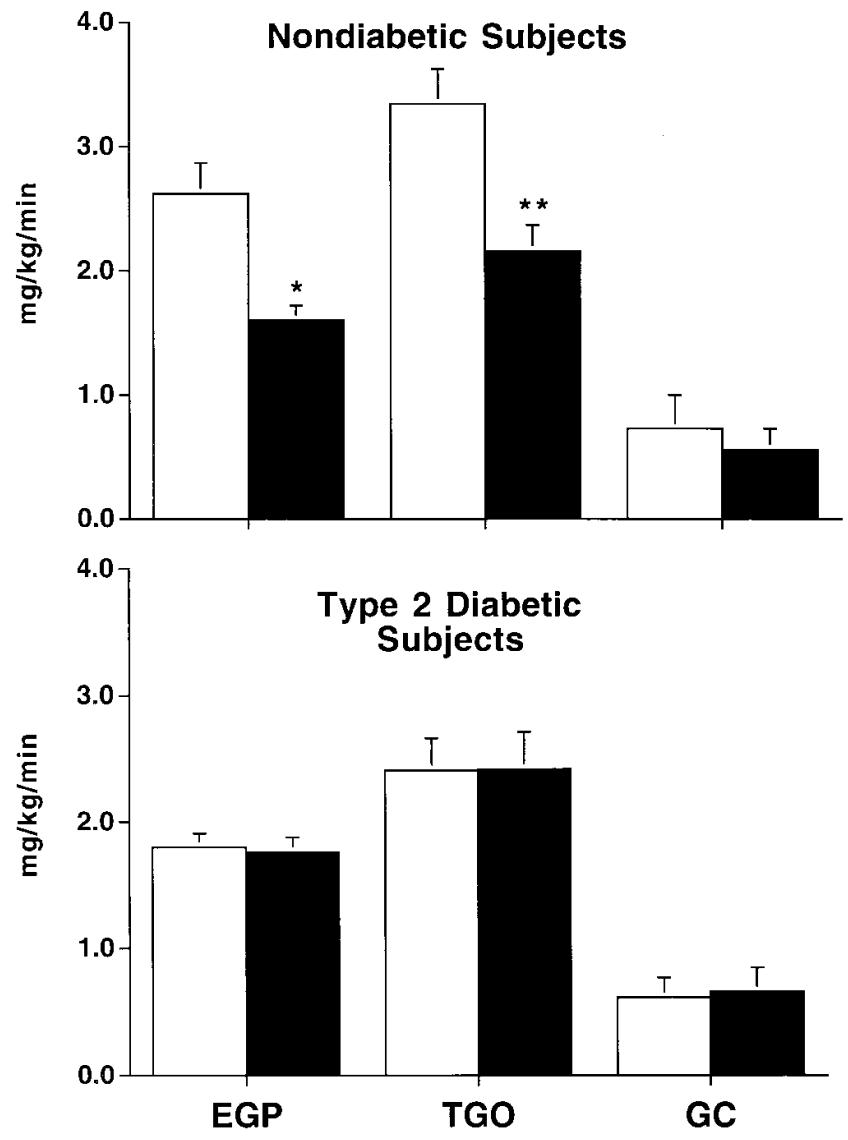

Figure 7. Endogenous glucose production $(E G P)$, total glucose output $(T G O)$, and glucose cycling $(G C)$ in nondiabetic and Type 2 diabetic subjects during euglycemia (open bars) and hyperglycemia (filled bars). ${ }^{* *} P<0.01,{ }^{*} P<0.02$, hyperglycemia vs. euglycemia in nondiabetic subjects. See text for details. 


\section{Discussion}

To examine the effect of hyperglycemia, independent of hormonal signals, on the pathways of glucose production and disposal in DM2, we used a modification of the pancreatic and hyperglycemic clamp techniques. When euglycemia $(\sim 90 \mathrm{mg} /$ dl) was maintained throughout the duration of the study, the infusion of somatostatin with replacement of insulin, glucagon, and growth hormone did not cause any significant change in either peripheral glucose fluxes or EGP. However, in accordance with previous reports (14-17), we found that in nondiabetic individuals a doubling of the plasma glucose concentration (to $\sim 180 \mathrm{mg} / \mathrm{dl}$ ) stimulated peripheral glucose uptake by $69 \%$ and suppressed EGP by $42 \%$. Conversely, under identical experimental conditions, the same degree of moderate hyperglycemia $(+90 \mathrm{mg} / \mathrm{dl})$ failed to lower EGP and less effectively promoted glucose disposal (by only $49 \%$ ) in patients with DM2. Consistent with the above tracer data, the rate of glucose infusion required to maintain hyperglycemia was decreased by $58 \%$ in the DM 2 compared with the nondiabetic individuals. These conclusions were virtually unchanged whether the glucose kinetics during hyperglycemia were compared with those at euglycemia on the day of the study or with those measured during the time control studies. Thus, the ability of ambient glucose (at basal insulin) to regulate glucose metabolism is severely impaired in this group of DM2 patients. This defect involves both blunted inhibition of EGP and decreased stimulation of glucose uptake.

In the present study the relative contributions of increased $\mathrm{Rd}$ and decreased EGP to "glucose effectiveness" in nondiabetic individuals were 64 and 36\%, respectively. These estimates are quite consistent with those recently reported in nondiabetic dogs by Ader et al. (41). In fact, these authors showed that glucose-stimulated Rd accounted for $71 \%$ of overall glucose effectiveness in dogs. Numerous studies have clearly demonstrated the presence of insulin resistance in DM2 $(1-5,21-$ $23)$. The most striking feature of peripheral insulin action in patients with DM2 is perhaps the almost complete inability to stimulate glucose storage into glycogen (6-11,21-23). This had long been suggested by indirect calorimetry and muscle biopsy data $(6,7,9-11)$ and more recently directly demonstrated by nuclear magnetic resonance spectroscopy (8). In this study, the ability of an equal increment in the plasma glucose concentration to promote glucose incorporation into glycogen was intact in patients with DM2. Using the same experimental methodology to assess glycogen synthesis during insulin clamp studies, we also found a marked defect in the ability of insulin to activate this pathway in patients with DM2 $(42,43)$. Thus, it appears that hyperglycemia at basal insulin was capable of completely normalizing glycogen synthesis in DM2. The ability of glucose per se to compensate for the defect in insulin-mediated glucose storage had been previously suggested by studies in DM2 (20-23) and in diabetic rats (44). In particular, Del Prato et al. reported marked impairment (by $75 \%$ ) in glycogen deposition in DM2 patients during euglycemic-hyperinsulinemic clamp studies (23). However, when the DM2 subjects were studied at the same hyperinsulinemic levels but in the presence of hyperglycemia, the rate of glycogen synthesis was more than normalized. Our results demonstrate that this effect is solely an effect of glucose, and that no background of hyperinsulinemia is needed for the compensating effect of glucose to occur. The biochemical mechanism responsible for this action is likely to involve a selective activation of the skeletal muscle glycogen synthase by glucose $(21,22,44)$.

We wish to caution against the extrapolation of the present results on the effects of hyperglycemia at basal insulin on peripheral glucose uptake to the condition of hyperglycemia in the absence of insulin. During the euglycemic periods of our study (and during the time control studies) we failed to detect a significantly lower rate of glucose uptake in the DM2 compared with the nondiabetic subjects. However, there was a tendency for the glucose $\mathrm{Rd}$ to be lower in the DM2 group at equal levels of ambient insulin. Since skeletal muscle glucose uptake represents a relatively small fraction of whole body glucose uptake at basal insulin $(2,45)$, we certainly cannot exclude a contribution of muscle insulin resistance during the pancreatic clamp studies in DM2 patients. That underlying defects in insulin action remained suggests that some impairment in peripheral insulin action may contribute to the decrease in whole body glucose uptake in DM2 during hyperglycemia. In fact, previous work has demonstrated preserved ability of glucose per se to stimulate muscle glucose uptake when assessed in the presence of marked insulin deficiency $(20,45)$.

In an attempt to investigate the mechanism whereby hyperglycemia inhibits EGP in nondiabetic but not in DM2 individuals, we also measured TGO and glucose cycling in subgroups of study subjects. The changes in EGP induced by hyperglycemia at basal insulin were virtually superimposable in these subgroups compared with the entire group of subjects with a $39 \%$ decrease in EGP in the nondiabetic individuals (vs. $42 \%$ in the entire group) and no change in the DM2 patients. The rate of TGO represents the total flux through glucose-6-phosphatase, and it was suppressed by $35 \%$ in the nondiabetic individuals but unchanged in the DM2 subjects. However, the rate of glucose cycling (defined as the futile cycling of glucose between glucose and glucose-6-phosphate) remained unchanged in both groups. A decline in the flux through glucose-6-phosphatase, as observed in the nondiabetic individuals during hyperglycemia, can be due to either decreased formation of glucose-6-phosphate and/or decreased activity of the glucose6-phosphatase complex (46). The rate of glucose cycling may help us to speculate on the prevalent mechanism. Thus, if the driving force for the decrease in TGO is a marked decrease in the formation of glucose-6-phosphate from glycogenolysis/gluconeogenesis the rate of glucose cycling may be expected to be increased. In fact, the increase in the flux through glucokinase due to hyperglycemia would be paralleled by a marked decrease in the formation of glucose-6-phosphate by other sources and glucose cycling should be increased. Conversely, if a decrease in glucose-6-phosphatase activity is the major determinant, glucose cycling may be unchanged or even decreased since the decrease in glucose-6-phosphatase activity would balance the increased flux through glucokinase. Finally, the lack of suppression of TGO by hyperglycemia in DM2 is consistent with deficient inhibition of glucose-6-phosphatase activity and/ or lack of inhibition of glucose-6-phosphate formation. However, the lack of increase in glucose cycling despite unchanged flux through glucose-6-phosphatase and hyperglycemia is highly suggestive that defective glucokinase activity is also a mechanism for this effect in DM2. Indeed, some of the alterations in glucose fluxes reported herein closely resemble those observed in animal models with decreased activity of glucokinase $(47,48)$.

Increased glucose cycling may be an early feature of DM2 
(29). In fact, in a group of mildly hyperglycemic DM2 patients, glucose cycling was increased two- to threefold in the postabsorptive state and after glucose infusion (29). In this study, we did not detect differences in the rates of glucose cycling between the nondiabetic subjects and the DM2 patients, most likely because we normalized the plasma glucose concentrations by low-dose overnight insulin infusion. This explanation is supported by data indicating that restoration of normoglycemia by insulin normalized elevated rates of glucose cycling in diabetic dogs (49). Most previous studies on the effects of glucose infusions on TGO and glucose cycling allowed insulin and other hormones to change $(29,30)$. Thus, the effect of a combined increase in plasma glucose and insulin was examined. Under these conditions, decreased TGO and lack of suppression of glucose cycling had been demonstrated. Bell et al. (17) also reported glucose-dependent decrease in TGO with lack of inhibition of glucose cycling in the presence of mild and fixed hyperinsulinemia in nondiabetic lean individuals. Our results in the nondiabetic group appear to confirm these previous findings. Together, these studies suggest that in humans hyperglycemia inhibits EGP largely via inhibition of glucose-6-phosphatase in the presence of increased flux through glucokinase. Furthermore, the present results suggest that the actions of ambient glucose on both these processes-fluxes through glucokinase and glucose-6-phosphatase-are impaired in DM2.

There remains a great deal of controversy regarding the role of glucose or hyperglycemia in the physiological regulation of EGP and hepatic glucose uptake, particularly in states of altered glucose tolerance. Defective stimulation of splanchnic glucose uptake during oral glucose administration has been reported in DM2 in most studies (50-52). Examining the metabolic effects of postprandial glycemia in DM2, Alzaid et al. (53) reported that the ability of glucose per se to inhibit EGP was preserved in subjects with DM2. However, the effect of hyperglycemia was examined during moderate hyperinsulinemia (mimicking a postprandial insulin profile). Under these conditions, insulin infusion had already caused a significant suppression of EGP, even prior to the induction of hyperglycemia. More recently Basu et al. (26) directly examined the regulation of glucose effectiveness in DM2 at basal insulin. Their experimental approach differed from ours in several features. In particular, Basu et al. infused glucose at a fixed rate during pancreatic clamp conditions in DM2 and nondiabetic individuals. That the increment in the plasma glucose concentration was much higher in the DM2 patients than in the nondiabetic subjects indicated a severe defect in glucose effectiveness in the former. This finding is quite consistent with our observation of $\mathrm{a} \sim 60 \%$ decrease in the rates of glucose infusion required to maintain the same hyperglycemic plateau in DM2. Since in their study, the increment in the plasma glucose concentrations was higher in the DM2 subjects than in the nondiabetic individuals, mathematical modeling of the results was used to estimate the effects of equivalent increases in the ambient glucose concentrations on $\mathrm{Rd}$ and EGP in the two groups. The latter calculation revealed decreased ability of glucose to regulate its own disposal. Furthermore, while it did not reach statistical significance, an $\sim 30 \%$ decrease in the ability of glucose to inhibit EGP was also demonstrated in DM2. Thus, despite important differences in the experimental design, the major conclusions of our study and of this previous work are consistent.

The plasma FFA concentrations were higher in the DM2 than those in the nondiabetic group during the euglycemic and the hyperglycemic periods of the protocols. Can these differences in plasma FFA concentrations account for the lack of glucose-mediated suppression of glucose production in DM2? Elevations in the circulating levels of FFA and/or in the rates of lipid oxidation can antagonize the actions of insulin on both glucose production and uptake (54-59). Of note, in this study, plasma FFA concentrations did not differ between euglycemic and hyperglycemic periods in the diabetic subjects. Furthermore, the rates of glucose and lipid oxidation were comparable in the two groups and during all time periods. Thus, if the circulating FFA exerted a stimulatory action on EGP in the DM2 group, this effect was selective for the hyperglycemic period, since it was not observed during either the time control studies or the euglycemic periods. The latter finding suggests that differences in the circulating FFA levels within this relatively low range did not play a major role in the regulation of EGP in the presence of basal insulin (59). Overall, while it is unlikely that differences in circulating FFA would account for the complete lack of inhibition of EGP we observed in the diabetic subjects, we cannot exclude that the presence of moderately elevated FFA levels contributed to our findings. Further studies designed to specifically address the role of plasma FFA in glucose-induced inhibition of EGP will be needed to conclusively address this possibility.

Some additional comments on specific features of our experimental design are warranted. We examined the effect of hyperglycemia on hepatic glucose fluxes in DM2 individuals after overnight "basal" insulinization. While this procedure is needed to generate normoglycemia in DM2 in the absence of increases in counterregulatory hormones, it may be argued that overnight insulinization is likely to reverse some of the metabolic defects of DM2. In particular, it is evident that in our patients the rates of glucose cycling and EGP were normalized. While the plasma insulin concentration was higher in DM2 than in nondiabetic individuals before initiation of the pancreatic clamp procedure, ambient insulin and insulin requirements were similar in the two groups thereafter. This was again observed over $4 \mathrm{~h}$ on the day of the hyperglycemic challenge and over $6 \mathrm{~h}$ during the time-control study. Thus, it appears that the action of insulin on EGP was normalized by overnight insulin infusion when examined under identical hormonal conditions. It should also be pointed out that while we have attempted to "reconstruct" a quasi-basal hormonal condition during our pancreatic clamp procedure, it is clear that true basal hormonal conditions cannot be generated with this protocol in humans. Since insulin and glucagon were infused systemically, it is likely that a state of mild peripheral hyperinsulinemia prevailed during the studies. It is also likely that the portal ratio of glucagon to insulin may have been slightly increased compared with true basal conditions. Overall, while we found some comfort in the observation that the rates of glucose uptake and EGP were very similar to those seen under basal postabsorptive conditions, we cannot rule out the possibility that the small increase in circulating insulin from the ambient level may have sensitized the liver to subsequent suppression by hyperglycemia in the nondiabetic individuals. Most important, our experimental design generated stable near-basal hormonal conditions during either hyperglycemia or euglycemia and thus allowed us to assess the direct effects of changes in ambient glucose per se in the same individuals.

In summary, our results provide strong support to the no- 
tion that glucose effectiveness is decreased in DM2. Under basal insulin conditions, this is due to both lack of glucosemediated suppression of EGP and diminished stimulation of glucose uptake. The mechanism for the impaired regulation of EGP by glucose is likely to involve defective modulation of the fluxes through glucokinase and glucose-6-phosphatase. Conversely, glycogen synthesis in Type 2 diabetes is exquisitely sensitive to changes in plasma glucose concentrations in the presence of near-basal insulin levels.

\section{Acknowledgments}

The authors thank Robin Sgueglia and Anne Thomashunis, R.N., for their technical assistance.

This work was supported by grants from the National Institutes of Health (DK-45024 and DK-48321), the American Diabetes Association and the General Clinical Research Center (RR-12248), and by the Albert Einstein Diabetes Research and Training Center (DK20541)

\section{References}

1. Kimmerling, G., C. Javorsky, J.M. Olefsky, and G. Reaven. 1976. Demonstration of insulin resistance in untreated adult-onset diabetic subjects with fasting hyperglycemia. Diabetes. 25:673-678.

2. DeFronzo, R.A. 1988. The triumvirate. B-cell, muscle, liver. A collusion responsible for NIDDM. Diabetes. 37:667-687.

3. Bogardus, C., S. Lillioja, B.V. Howard, G. Reaven, and D. Mott. 1984. Relationships between insulin secretion, insulin action, and fasting plasma glucose concentration in nondiabetic and noninsulin-dependent diabetes mellitus. J. Clin. Invest. 74:1238-1246.

4. Kolterman, O.G., R.S. Gray, J. Griffin, P. Burstein, J. Insel, J.A. Scarlett, and J.M. Olefsky. 1981. Receptor and postreceptor defects contribute to the insulin resistance in noninsulin-dependent diabetes mellitus. J. Clin. Invest. 68: 957-959.

5. Rizza, R.A., L.J. Mandarino, and J.E. Gerich. 1981. Mechanism and significance of insulin resistance in noninsulin-dependent diabetes mellitus. Diabetes. 30:990-995.

6. Thorburn, A.W., B. Gumbiner, F. Bulacan, P. Wallace, and R.R. Henry. 1990. Intracellular glucose oxidation and glycogen synthase activity are reduced in non-insulin-dependent (Type II) diabetes independent of impaired glucose uptake. J. Clin. Invest. 85:522-529.

7. Young, A.A., C. Bogardus, D. Wolfe-Lopez, and D.M. Mott. 1988. Muscle glycogen synthesis disposition of infused glucose in humans with reduced rates of insulin-mediated carbohydrate storage. Diabetes. 37:303-308.

8. Shulman, G.I., D.L. Rothman, T. Jue, P. Stein, R.A. DeFronzo, and R.G. Shulman. 1990. Quantitation of muscle glycogen synthesis in normal subjects and subjects with non-insulin-dependent diabetes by ${ }^{13} \mathrm{C}$ nuclear magnetic resonance spectroscopy. N. Engl. J. Med. 322:223-228.

9. Wright, K.S., H. Beck-Nielsen, O.G. Kolterman, and L.J. Mandarino. 1988. Decreased activation of skeletal muscle glycogen synthase by mixed-meal ingestion in NIDDM. Diabetes. 37:436-440.

10. Bogardus, C., L. Lillioja, K. Stone, and D. Mott. 1984. Correlation between muscle glycogen synthase activity and in vivo insulin action in man. $J$. Clin. Invest. 73:1186-1190.

11. Lillioja, S., D.M. Mott, J.K. Zawadzki, A.A. Young, W.G. Abbott, and C. Bogardus. 1986. Glucose storage is a major determinant of in vivo "insulin resistance" in subjects with normal glucose tolerance. J. Clin. Endocrinol. Metab. 62:922-927.

12. Soskin, S., and R. Levine. 1946. Carbohydrate Metabolism. University of Chicago Press, Chicago. 247-263.

13. Glinsman, W.H., E.P. Hern, and A. Lynch. 1969. Intrinsic regulation of glucose output by rat liver. Am. J. Physiol. 216:698-703.

14. Sacca, L., R. Hendler, and R.S. Sherwin. 1979. Hyperglycemia inhibits glucose production in man independent of changes in glucoregulatory hormones. J. Clin. Endocrinol. Metab. 47:1160-1163.

15. Shulman, G.I., J.E. Lijenquist, P.E. Williams, W.W. Lacy, and A.D. Cherrington. 1978. Glucose disposal during insulinopenia somatostatin-treated dogs. The roles of glucose and glucagon. J. Clin. Invest. 62:487-491.

16. Shulman, G.I., W.W. Lacy, J.E. Lijenquist, U. Keller, P.E. Williams, and A.D. Cherrington. 1980. Effect of glucose, independent of changes in insulin and glucagon secretion, on alanine metabolism in the conscious dog. J. Clin. Invest. 65:496-505.

17. Bell, P.M., R.G. Firth, and R.A. Rizza. 1986. Effects of hyperglycemia on glucose production and utilization in humans. Measurements with $\left[2^{3} \mathrm{H}\right]-$, $\left[3^{3} \mathrm{H}\right]-$, and $\left[6^{14} \mathrm{C}\right]$-glucose. Diabetes. 35:642-648.

18. Ader, M., G. Pacini, Y.J. Ysug, and R.N. Bergman. 1985. Importance of glucose per se to intravenous glucose tolerance. Comparison of the minimal model prediction with direct measurements. Diabetes. 34:1092-1103.

19. Ferrannini, E., L. Locatelli, and J.P. Felber. 1989. Differential effects of insulin and hyperglycemia on intracellular glucose dispositions in humans. $\mathrm{Me}$ tabolism. 38:459-65.

20. Capaldo, B., D. Santoro, G. Riccardi, N. Perrotti, and L. Sacca. 1986. Direct evidence for a stimulatory effect of hyperglycemia per se on peripheral glucose disposal in type 2 diabetes. J. Clin. Invest. 77:1285-1290.

21. Vaag, A., P. Dambso, O. Hother-Nielsen, and H. Beck-Nielsen. 1992. Hyperglycemia compensates for the defects in insulin-mediated glucose metabolism and in the activation of glycogen synthase in the skeletal muscle of patients with type 2 diabetes mellitus. Diabetologia. 35:80-88.

22. Kelley, D.E., and L.J. Mandarino. 1990. Hyperglycemia normalizes insulin-stimulated skeletal muscle glucose oxidation and storage in noninsulindependent diabetes mellitus. J. Clin. Invest. 86:1999-2007.

23. Del Prato, S., R.C. Bonadonna, E. Bonora, G. Gulli, A. Solini, M. Shank, and R.A. DeFronzo. 1993. Characterization of cellular defects of insulin action in Type 2 (non-insulin-dependent) diabetes mellitus. J. Clin. Invest. 91: 484-494.

24. Welch, S., S.S.P. Gebhart, R.N. Bergman, and L.S. Phillips. 1990. Minimal model analysis of intravenous glucose tolerance test-derived insulin sensitivity in diabetic subjects. J. Clin. Endocrinol. Metab. 71:1508-1518.

25. Saad, M.F., R.L. Anderson, A. Laws, R.M. Watanabe, W.W. Kades, Y.-D.I. Chen, R.E. Sands, D. Pei, P.J. Savage, and R.N. Bergman. 1994. A comparison between the minimal model and the glucose clamp in the assessment of insulin sensititvity across the spectrum of glucose tolerance. Diabetes. 43:11141121.

26. Basu, A., A. Caumo, F. Bettini, A. Gelisio, A. Alzaid, C. Cobelli, and R.A. Rizza. 1997. Impaired basal glucose effectiveness in NIDDM. Contribution of defects in glucose disappearance and production, measured using an optimized minimal model independent protocol. Diabetes. 46:421-432.

27. DeFronzo, R.A., E. Ferrannini, R. Hendler, P. Felig, and J. Wahren. 1983. Regulation of splanchnic and peripheral glucose uptake by insulin and hyperglycemia in man. Diabetes. 32:35-45.

28. Ludvik, B., J.J. Nolan, A. Roberts, J. Baloga, M. Joyce, J.M. Bell, and J.M. Olefsky. 1995. A noninvasive method to measure splanchic glucose uptake after oral glucose administration. J. Clin. Invest. 95:2232-2238.

29. Efendic, S., S. Karlander, and M. Vranic. 1988. Mild type II diabetes markedly increases glucose cycling in the post-absorptive state and during glucose infusion irrespective of obesity. J. Clin. Invest. 81:1953-1961.

30. Miyoshi, H., G.I. Shulman, E.J. Peters, M.H. Wolfe, D. Elahi, and R.R. Wolfe. 1988. Hormonal control of substrate cycling in humans. J. Clin. Invest. 81:1545-1555

31. Shamoon, H., S. Friedman, C. Canton, L. Zacharowicz, M. Hu, and L. Rossetti. 1994. Increased epinephrine and skeletal muscle responses to hypoglycemia in noninsulin-dependent diabetes mellitus. J. Clin. Invest. 93:25622571.

32. Finegood, D.T., R.N. Bergman, and M. Vranic. 1987. Estimation of endogenous glucose production during hyperinsulinemic-euglycemic glucose clamp: comparison of unlabeled and labeled glucose infusates. Diabetes. 36: 914-924.

33. Dunn, A., J. Katz, S. Golden, and M. Chenoweth. 1976. Estimation of glucose turnover and recycling in rabbits using various $\left({ }^{3} \mathrm{H},{ }^{14} \mathrm{C}\right)$ labels. $A m$. $J$. Physiol. 230:1159-1162.

34. Sotsky, M.J., S. Shilo, and H. Shamoon. 1989. Regulation of counterregulatory hormone secretion in man during exercise and hypoglycemia. J. Clin. Endocrinol. Metab. 68:9-17.

35. Gawehn, K. 1986. D-Lactate. In Methods of Enzymatic Analysis. H. Bergmeyer and M. Gassl, editors. Academic Press, Inc., New York. 6:583-592.

36. Hawk, P. 1947. The Kjeldahl method. In Practical Physiological Chemistry. 12th ed. Toronto, Blakiston. 814-822.

37. Steele, R. 1959. Influences of glucose loading and of injected insulin on hepatic glucose output. Ann. NY Acad. Sci. 82:420-430.

38. Rossetti, L., and A. Giaccari. 1990. Relative contribution of glycogen synthesis and glycolysis to insulin-mediated glucose uptake. A dose-response euglycemic clamp study in normal and diabetic rats. J. Clin. Invest. 85:17851792 .

39. Rossetti, L., Y.-T. Lee, J. Ruiz, S. Aldridge, H. Shamoon, and G. Boden. 1993. Quantitation of glycolysis and skeletal muscle glycogen synthesis in humans. Am. J. Physiol. 265:E761-E769.

40. Lusk, G. 1924. Animal calorimetry: analysis of the oxidation of mixtures of carbohydrate and fat. J. Biol. Chem. 59:41-42.

41. Ader, M., T.-C. Ni, and R.N. Bergman. 1997. Glucose effectiveness assessed under dynamic and steady-state conditions. Comparability of uptake versus production components. J. Clin. Invest. 99:1187-1199.

42. Cohen, N., M. Halberstam, P. Shlimovich, C.J. Chang, H. Shamoon, and L. Rossetti. 1995. Oral vanadyl sulfate improves hepatic and peripheral insulin sensitivity in patients with non-insulin dependent diabetes mellitus. J. Clin. Invest. 95:2501-2509.

43. Halberstam, M., N. Cohen, L. Rossetti, and H. Shamoon. 1996. Oral va- 
nadyl sulfate enhances hepatic and peripheral insulin sensitivity in obese patients with NIDDM, but not in non diabetic obese subjects. Diabetes. 45:659666.

44. Farrace, S., and L. Rossetti. 1992. Hyperglycemia markedly enhances skeletal muscle glycogen synthase activity in diabetic, but not in normal conscious rats. Diabetes. 41:1453-1463.

45. Baron, A.D., G. Brechtel, P. Wallace, and S.V. Edelman. 1988. Rates and tissue sites of non-insulin- and insulin-mediated glucose uptake in humans. Am. J. Physiol. 255:E769-E774.

46. Rossetti, L., A. Giaccari, N. Barzilai, K. Howard, G. Sebel, and M. Hu. 1993. Mechanism by which hyperglycemia inhibits hepatic glucose production in conscious rats. Implications for the pathophysiology of fasting hyperglycemia. J. Clin. Invest. 92:1126-1134.

47. Barzilai, N., M. Hawkins, I. Angelov, M. Hu, and L. Rossetti. 1996. Glucosamine-induced inhibition of liver glucokinase impairs the ability of hyperglycemia to suppress endogeneous glucose production. Diabetes. 45:1329-1335.

48. Rossetti, L., W. Chen, M. Hu, M. Hawkins, N. Barzilai, and S. Efrat. 1997. Abnormal regulation of hepatic glucose production by hyperglycemia in mice with a disrupted glucokinase allele. Am. J. Physiol. 273:E743-E750.

49. Shi, Z.Q., A. Giacca, S. Fisher, H. Vidal, G. van de Werve, and M. Vranic. 1994. Importance of substrate changes in the decrease of hepatic glucose cycling during insulin infusion and declining glycemia in the depancreatectomized dog. Diabetes. 43:1284-1290.

50. Felig, P., J. Wahren, and R. Hendler. 1978. Influence of maturity-onset diabetes on splanchnic glucose balance after oral glucose ingestion. Diabetes. 27:121-126.

51. Firth, R., P. Marsh, I. Hansen, and R. Rizza. 1986. Postprandial hyperglycemia in patients with non-insulin-dependent diabetes mellitus: role of he- patic and extrahepatic tissues. J. Clin. Invest. 77:1525-1532.

52. Ludvik, B., J.J. Nolan, A. Roberts, J. Baloga, M. Joyce, J.M. Bell, and J.M. Olefsky. 1997. Evidence for decreased splanchic glucose uptake after oral glucose administration in non-insulin-dependent diabetes mellitus. J. Clin. Invest. 100:2354-2361.

53. Alzaid, A.A., S.F. Dinneen, D.J. Turk, A. Caumo, C. Cobelli, and R.A. Rizza. 1994. Assessment of insulin action and glucose effectiveness in diabetic and nondiabetic humans. J. Clin. Invest. 94:2341-2348.

54. Rebrin, K., G.M. Steil, L. Getty, and R.N. Bergman. 1995. Free fatty acid as a link in the regulation of hepatic glucose output by peripheral insulin. Diabetes. 44:1038-1045.

55. Rebrin, K., G.M. Steil, S.D. Mittelman, and R.N. Bergman. 1996. Causal linkage between insulin suppression of lipolysis and suppression of liver glucose output in dogs. J. Clin. Invest. 98:741-749.

56. Sindelar, D.K., C.A. Chu, M. Rohlie, D.W. Neal, L.L. Swift, and A.D. Cherrington. 1997. The role of fatty acids in mediating the effects of peripheral insulin on hepatic glucose production in the conscious dog. Diabetes. 46:187196

57. Lewis, G.F., M. Vranic, P. Harley, and A. Giacca. 1997. Fatty acids mediate the acute extrahepatic effects of insulin on hepatic glucose production in humans. Diabetes. 46:1111-1119.

58. Boden, G., X. Chen, J. Ruiz, J.V. White, and L. Rossetti. 1994. Mechanisms of fatty acids induced inhibition of glucose uptake. J. Clin. Invest. 93: 2438-2446.

59. Puhakainen, I., and H. Yki-Jarvinen. 1993. Inhibition of lipolysis decreases lipid oxidation and gluconeogenesis from lactate but not fasting hyperglycemia or total hepatic glucose production in NIDDM. Diabetes. 42:16941699. 